COSTA, C.A. CASALI, V.W.D. RUIZ, H.A. JORDÃO, C.P. CECON, P.R. Teor de metais pesados e produção de alface adubada com composto de lixo urbano. Horticultura Brasileira, Brasília, v. 19 n. 01, p. 10-16, março 2001.

\title{
Teor de metais pesados e produção de alface adubada com composto de lixo urbano.
}

\author{
Cândido A. Costa ${ }^{1}$, Vicente Wagner D. Casali ${ }^{2}$, Hugo Alberto Ruiz ${ }^{3}$, Cláudio P. Jordão ${ }^{4}$ Paulo Roberto \\ Cecon $^{5}$
}

${ }^{1}$ UFMG-NCA, C. Postal 135, 39.404-006 Montes Claros-MG; ${ }^{2}$ UFV-Depto. Fitotecnia; ${ }^{3}$ UFV-Depto. Solos e Nutrição de Plantas; ${ }^{4}$ UFVDepto. Química e ${ }^{5}$ UFV-Depto. Informática, 36.571-000, Viçosa-MG. E-mail: candido@ mail.connect.com.br.

\section{RESUMO}

Avaliou-se o emprego do composto de lixo urbano em três cultivos sucessivos da alface. O experimento foi realizado em campo, em Viçosa no período de outubro/95 a junho/96 num Latossolo Vermelho-Amarelo. Os tratamentos consistiram de quatro doses de composto de lixo $\left(0,10,20\right.$ e $\left.30 \mathrm{t} \mathrm{ha}^{-1}\right)$ e três cultivares de alface ('Regina', 'Vitória' Verde Clara' e 'Brasil - 303'), arranjadas no esquema fatorial 4 × 3 , no delineamento em blocos casualizados, com quatro repetições, totalizando 48 parcelas. Cada parcela experimental foi constituída por quatro fileiras de cinco plantas, no espaçamento 25 x $30 \mathrm{~cm}$, sendo as três linhas centrais consideradas como parcela. $\mathrm{O}$ composto foi adicionado apenas no primeiro cultivo. Determinouse o peso da matéria fresca e da matéria seca da parte aérea das plantas e o teor de $\mathrm{Zn}, \mathrm{Cu}, \mathrm{Pb}, \mathrm{Cd}$, $\mathrm{Ni}$ e $\mathrm{Cr}$ na matéria seca do tecido vegetal, após a colheita no primeiro, segundo e terceiro cultivos, correspondente a 46, 142 e 222 dias da aplicação do composto, respectivamente. Houve aumento significativo da produção em resposta às doses do composto, principalmente no primeiro cultivo, em que as cultivares 'Regina', 'Vitória Verde Clara' e 'Brasil-303' produziram, respectivamente, 333,$82 ; 337,81$ e 303,60 g.planta ${ }^{-1}$ (peso fresco). No segundo cultivo, o efeito diminuiu. Já no terceiro cultivo, não houve efeito do composto sobre a produção. $\mathrm{O}$ teor de metais pesados na planta foi aumentado, principalmente no primeiro cultivo, seguindo a seguinte ordem decrescente: $\mathrm{Pb}>\mathrm{Cd}>\mathrm{Cu}>\mathrm{Zn}$. No segundo cultivo, o efeito foi menor e no terceiro cultivo não houve efeito do composto, o que foi atribuído ao esgotamento do seu efeito. Nenhum dos elementos atingiu níveis considerados fitotóxicos.

Palavras-chave: Lactuca sativa L., adubação orgânica, fitotoxicidade.

\section{ABSTRACT}

Level of heavy metals and yield of lettuce fertilized with urban solid waste compost.

A field experiment was carried out to evaluate the influence of fertilization with urban solid waste on the level of heavy metal and yield of lettuce cultivars after three successive crops. The experiment was carried out from October/95 to June/96 under field conditions, in Viçosa (Brazil), on Yellow Red Latosol soil. The experimental design was of complete randomized blocks, with treatments distributed in a factorial cheme $4 \times 3$ (four levels of compost - 0,10 , 20 and $30 \mathrm{t} \mathrm{ha}^{-1} \mathrm{x}$ three cultivars - 'Regina', 'Vitória Verde Clara' and 'Brasil-303'), with four replications. Each plot was constituted of 20 plants, spaced $25 \times 30 \mathrm{~cm}$, where data were collected from the three central plants. Fresh and dry weight matter and $\mathrm{Zn}, \mathrm{Cu}, \mathrm{Pb}$, $\mathrm{Cd}, \mathrm{Ni}$ and $\mathrm{Cr}$ content were determined after 46, 142 and 222 days of application, respectively. Yield increased with higher compost rates, particularly on first crop, where 'Regina', 'Vitória Verde Clara' and 'Brasil-303' produced 333.82; 337.81 and 303.60 g.plant $^{-1}$ (fresh weight), respectively. On the second crop, there was little effect and on the third crop, there was not influence of compost on the yields. Levels of heavy metals content in plants was increased as an effect of the compost, in the following order: $\mathrm{Pb}>\mathrm{Cd}>\mathrm{Cu}>\mathrm{Zn}$. On the second crop, the effect was intermediate and the third crop, was not influence by compost, indicating consequent decrease in the influence of compost on level of heavy metals in plant. No heavy metals were detected in toxic level to the plant.

Keywords: Lactuca sativa L., organic manure, phitotoxicity, recycle.

(Aceito para publicação em 05 de fevereiro de 2.001)

$\mathrm{N}^{\circ}$ os últimos anos, difundiu-se basante o uso de resíduos urbanos como matéria-prima para obtenção de fertilizante orgânico. Dentre esses, o lixo domiciliar tem despertado grande interesse, pois sua utilização permite a reciclagem de nutrientes e o seu acúmulo vem constituindo sérios problemas ambientais, principalmente nas grandes cidades (Ogata, 1983; Glória, 1992; He et al., 1995; Paino et al., 1996).

O composto orgânico de lixo urbano, por ter boa capacidade melhoradora das condições químicas, biológicas e físicas dos solos, causa efeitos no cres- cimento e desenvolvimento das plantas. Muitos são os trabalhos que registram os efeitos positivos desse composto sobre a produção das plantas, principalmente nas espécies olerícolas. Já foram constatados aumentos significativos na produção, como conseqüente efeito do composto orgânico de lixo, na cultura do tomate (Fritz \& Venter, 1988; Weir \& Allen, 1997), espinafre (Fritz \& Venter, 1988; Dixon et al. , 1995), rabanete (Fritz \& Venter, 1988), abóbora italiana (Dixon et al., 1995), feijão-vagem (Dixon et al., 1995), cenoura (Fritz \& Venter, 1988; Costa et al., 1997) e alfa- ce (Fritz \& Venter, 1988; Costa et al., 1994; Dixon et al., 1995).

Woodbury (1992), cita o composto orgânico de lixo urbano como grande supridor de micronutrientes, como $\mathrm{Zn}$, $\mathrm{Cu}$ e B, além de melhorar a capacidade de retenção de água e estimular a atividade microbiológica dos solos. Tais benefícios explicam o efeito positivo que o composto proporciona no crescimento e desenvolvimento das plantas.

Por outro lado, o composto pode também resultar em efeitos negativos na planta, levando a um menor crescimento. Costa et al. (1994) observaram efei- 
to negativo do composto na produção de matéria seca da alface e da cenoura quando se aplicava doses acima de 20 t.ha- ${ }^{1}$. Hernández et al. (1992), constataram diminuição no crescimento das plantas em doses acima de 60 t.ha-1. Tais autores atribuíram esse resultado ao teor de sais, principalmente de $\mathrm{NaCl}$, que é comumente encontrado em composto orgânico de resíduos urbanos.

O efeito depressivo do composto também pode ser atribuído aos metais pesados veiculados no composto, os quais, sendo absorvidos pelas plantas em grandes quantidades, podem atingir níveis fitotóxicos. Costa (1994), quando aplicou 90 t.ha- $^{1}$ de composto orgânico de lixo urbano no solo, observou redução drástica do crescimento da alface e da cenoura. Esse autor atribuiu tal efeito do composto ao elevado teor de $\mathrm{Cu}$ no tecido vegetal, além do elevado $\mathrm{pH}$ e condutividade elétrica dos solos.

O emprego de compostos orgânicos de lixo na agricultura brasileira vem aumentando consideravelmente na medida em que mais usinas de beneficiamento de lixo são construídas. Esses compostos orgânicos são utilizados principalmente pelos agricultores circunvizinhos das usinas, em sua maioria produtores de hortaliças.

Entre as olerícolas, destaca-se a alface por ser intensivamente cultivada, demandando, portanto, grandes quantidades de fertilizantes orgânicos.

Este trabalho teve por objetivo avaliar a produção de alface cultivada com composto de lixo urbano em três cultivos sucessivos e o teor de metais pesados na matéria seca vegetal.

\section{MATERIAL E MÉTODOS}

O experimento foi conduzido em área da Universidade Federal de Viçosa, no período de 09 de outubro de 1995 a 10 de junho de 1996, num Latossolo Vermelho-Amarelo distrófico, textura argilosa.

Os tratamentos consistiram de quatro doses de composto de lixo $(0,10,20$ e $\left.30 \mathrm{t} \mathrm{ha}^{-1}\right)$ e três cultivares de alface ('Regina', 'Vitória Verde Clara' e 'Brasil - 303'), arranjadas no esquema fatorial 4 x 3, no delineamento em blocos casualizados, com quatro repetições,

Tabela 1. Características físicas e químicas do solo e do composto orgânico de lixo urbano na época da incorporação ao solo. Viçosa, UFV, 1995.

\begin{tabular}{|c|c|c|}
\hline \multirow{2}{*}{ Características } & \multicolumn{2}{|c|}{ Valor } \\
\hline & Solo ${ }^{1}$ & Composto $^{2}$ \\
\hline pH em água $(1: 2,5)$ & 6,10 & 6,70 \\
\hline P disponível (mg dm-3) & 52,50 & 350,00 \\
\hline K disponível (mg dm-3) & 245,00 & $3.080,00$ \\
\hline Ca trocável (cmolc dm-3) & 4,20 & 41,50 \\
\hline Mg trocável (cmolc dm-3) & 1,0 & 6,80 \\
\hline $\mathrm{Zn}(\mathrm{mg} \mathrm{dm}-3)$ & 3,00 & 670,38 \\
\hline $\mathrm{Cu}(\mathrm{mg} \mathrm{dm}-3)$ & 2,56 & 390,00 \\
\hline Cd (mg dm-3) & 0,02 & 1,93 \\
\hline $\mathrm{Pb}$ (mg dm-3) & n.d.* & 368,11 \\
\hline $\mathrm{Ni}(\mathrm{mg} \mathrm{dm}-3)$ & 0,33 & 36,50 \\
\hline $\mathrm{Cr}$ (mg dm-3) & 0,32 & 97,04 \\
\hline Areia grossa (g kg-1) & 200,00 & - \\
\hline Areia fina (g kg-1) & 120,00 & - \\
\hline Silte3 (g kg-1) & 180,00 & - \\
\hline Argila3 (g kg-1) & 510,00 & - \\
\hline Classe textural & Argila & - \\
\hline
\end{tabular}

\footnotetext{
${ }^{1}$ Extrator químico: Mehlich-I (Defelipo \& Ribeiro, 1981)

${ }^{2}$ Extrator químico: $\mathrm{HNO}_{3} / \mathrm{HClO}_{4}$

* Não detectado.
}

totalizando 48 parcelas. Cada parcela experimental foi constituída por quatro fileiras de cinco plantas no espaçamento $25 \times 30 \mathrm{~cm}$, sendo as três linhas consideradas como parcela útil.

O composto foi fornecido pela usina de reciclagem e compostagem de lixo urbano da Companhia Municipal de Limpeza Urbana do Rio de Janeiro (COMLURB). As características físicas e químicas do solo e do composto na época da incorporação são apresentadas na Tabela 1.

Foram conduzidos três cultivos sucessivos de alface, com a adição do composto apenas no primeiro cultivo, um dias antes do transplantio das mudas, ou seja: primeiro cultivo (da semeadura à colheita), no período de 5 de outubro a 11 de dezembro de 1995; segundo cultivo, de 16 de janeiro a 20 de março de 1996; e terceiro cultivo, de 09 de abril a 10 de junho de 1996. A colheita no primeiro, segundo e terceiro cultivos, correspondeu a 46, 142 e 222 dias da aplicação do composto, respectivamente.

As colheitas foram feitas pela manhã, cortando as plantas rente ao solo e pesando imediatamente toda a parte aérea, para a determinação do peso da matéria fresca. Em seguida, o material vegetal foi colocado para secar em estufa a $65^{\circ} \mathrm{C}$ até peso constante, sendo, então, determinado o peso da matéria seca.

As raízes foram retiradas do solo, lavadas e também conduzidas para secagem em estufa com ventilação forçada a $65^{\circ} \mathrm{C}$ até peso constante, visando a análises químicas.

Na preparação das amostras para as análises químicas, a matéria seca da parte aérea foi separada em caule e folhas. Todo o material vegetal seco, tanto caule e folhas quanto raízes da alface, foi moído em moinho tipo Willey e passado em peneira com malha de 20 mesh de abertura.

As amostras foram mineralizadas com a mistura nítrico-perclórica, sendo determinados os teores de $\mathrm{Zn}, \mathrm{Cu}, \mathrm{Pb}$, $\mathrm{Cd}, \mathrm{Ni}$ e $\mathrm{Cr}$. As leituras foram feitas em espectrofotômetro de absorção atômica.

Os resultados foram analisados estatisticamente, por meio das análises de variância e regressão. As médias foram 
Tabela 2. Produção de matéria fresca (MF) e de matéria seca (MS) da parte aérea de três cultivares de alface, no segundo cultivo, adubadas com diferentes doses de composto de lixo urbano. Viçosa, UFV, 1995/96.

\begin{tabular}{llc}
\hline \multirow{2}{*}{ Cultivar } & \multicolumn{1}{c}{ MF } & MS \\
\cline { 2 - 3 } \multicolumn{2}{c}{ g.planta-1 $^{-1}$} \\
\hline Regina & $282,87 \mathrm{a}^{*}$ & $19,64 \mathrm{a}$ \\
Vitória & $269,84 \mathrm{a}$ & $18,75 \mathrm{a}$ \\
BR-303 & $161,01 \quad \mathrm{~b}$ & $9,89 \quad \mathrm{~b}$ \\
\hline
\end{tabular}

*As médias seguidas da mesma letra na coluna não diferem entre si, a $5 \%$ de probabilidade, pelo teste de Tukey.

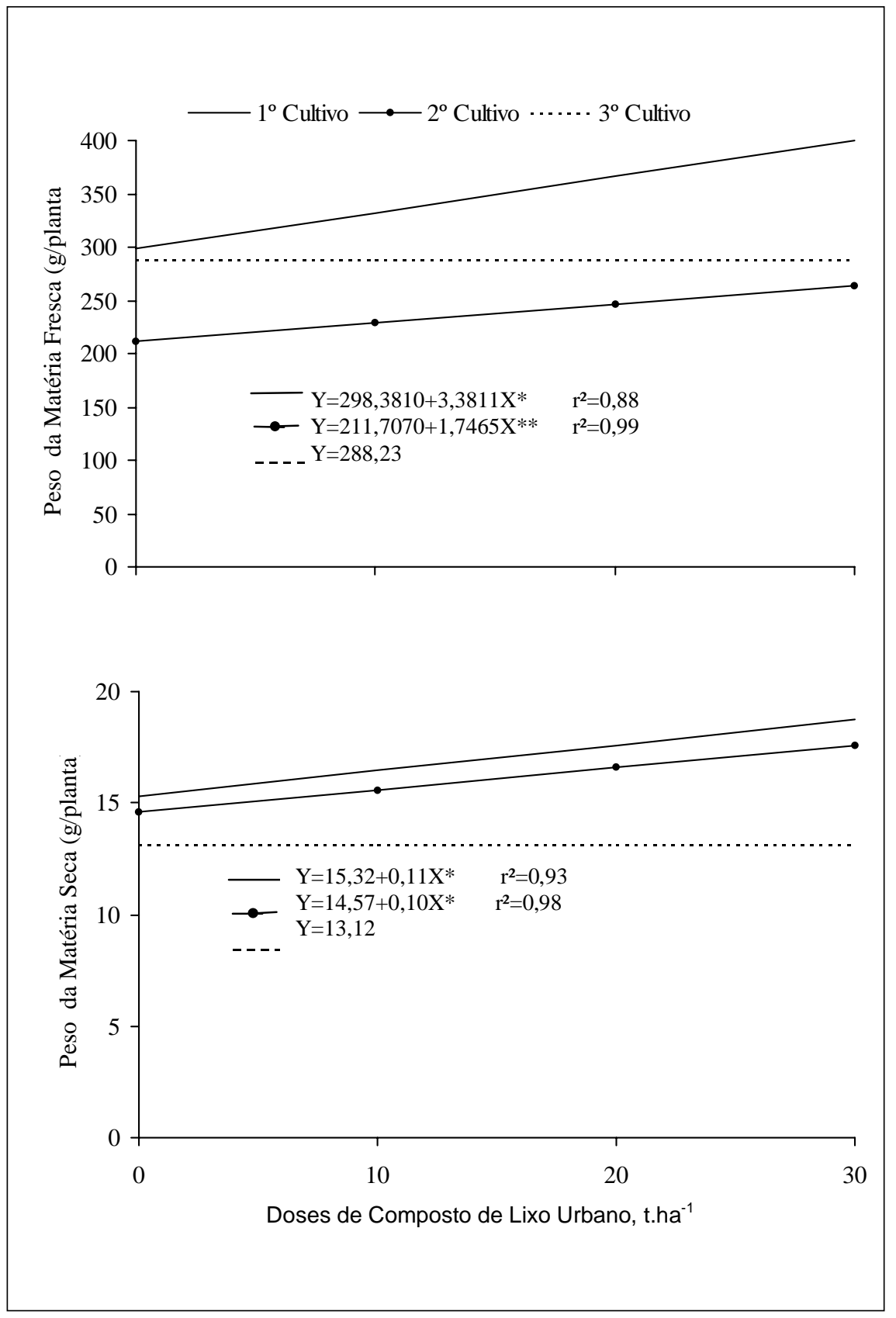

Figura 1. Produção de matéria fresca e de matéria seca da parte aérea da alface em três cultivos sucessivos, em função do uso de doses de composto orgânico de lixo urbano. Viçosa, UFV, 1995/96. comparadas pelo teste de Tukey, adotando-se o nível de $5 \%$ de probabilidade. As equações foram ajustadas, testando-se os coeficientes de determinação pelo teste $\mathrm{F}$.

\section{RESULTADOS E DISCUSSÃO}

\section{Produção de matéria fresca e de matéria seca}

A produção de matéria fresca foi influenciada $(\mathrm{p}<0,05)$ pelas doses de composto, no primeiro e segundo cultivo e pela cultivar apenas no segundo cultivo. No terceiro cultivo, não houve diferenças significativas em nenhum dos tratamentos. No segundo cultivo, a produção de matéria seca foi influenciada apenas pela cultivar. A interação dose de composto x cultivar, não foi significativa em nenhum dos casos.

No segundo cultivo, as cultivares 'Regina' e 'Vitória' tiveram maior produção de matéria fresca e de matéria seca do que 'Brasil-303' (Tabela 2). Como no primeiro e no terceiro cultivos não houve diferença significativa $(\mathrm{p}<0,05)$ entre as cultivares na produção de matéria fresca e matéria seca, as condições ambientais típicas de verão, em fevereiro e março, foram mais desfavoráveis à cultivar 'Brasil-303', resultando em menor produção, o que foi confirmado pelo maior pendoamento dessa cultivar.

As doses do composto provocaram aumento linear da produção de matéria fresca e de matéria seca das plantas do primeiro e segundo cultivos (Figura 1). No terceiro, o efeito não foi significativo.

$\mathrm{O}$ efeito positivo do composto na produção de alface nos dois primeiros cultivos é atribuído ao teor relativamente elevado de nutrientes essenciais às plantas (Tabela 1), além da melhoria nas condições físicas do solo. Tal efeito não foi constatado no último cultivo, porque a capacidade do composto em melhorar as condições físicas, químicas e biológicas do solo se esgotou, uma vez que foi feita apenas uma aplicação. Ainda, o tempo decorrido até o último cultivo foi suficiente para que houvesse a decomposição de grande parte da matéria orgânica do composto.

Paino et al. (1996), analisando o efeito do composto orgânico de lixo ur- 
Tabela 3. Médias dos teores de $\mathrm{Zn}, \mathrm{Cu}, \mathrm{Pb}, \mathrm{Cd}$, $\mathrm{Ni}$ e $\mathrm{Cr}$ na matéria seca das folhas (F), do caule (C) e das raízes (R) de três cultivares de alface adubadas com composto orgânico de lixo urbano. Viçosa, UFV, 1995/1996.

\begin{tabular}{|c|c|c|c|c|c|c|c|c|c|c|c|c|}
\hline \multirow{4}{*}{ Variável } & \multicolumn{12}{|c|}{ Cultivar } \\
\hline & Regina & Vitória & BR-303 & Regina & Vitória & BR-303 & Regina & Vitória & BR-303 & Regina & Vitória & BR-303 \\
\hline & \multicolumn{3}{|c|}{ Dose 0 t ha-1 } & \multicolumn{3}{|c|}{ Dose $10 \mathrm{t}$ ha- 1} & \multicolumn{3}{|c|}{ Dose $20 \mathrm{t}$ ha-1 } & \multicolumn{3}{|c|}{ Dose $30 \mathrm{t}$ ha- 1} \\
\hline & \multicolumn{12}{|c|}{$\mu \mathrm{g} g-1$} \\
\hline ZnC 3으 Cultivo & $63,10 \mathrm{a}$ & $58,45 \mathrm{~b}$ & $54,08 \mathrm{c}$ & $59,05 \mathrm{a}$ & $57,04 a b$ & $53,15 b$ & 68,38 a & $59,50 \mathrm{~b}$ & $56,85 b$ & 67,93 a & $55,85 \mathrm{~b}$ & $51,45 \mathrm{c}$ \\
\hline CuC 3ํㅡ Cultivo & $7,07 \mathrm{a}$ & $6,21 a b$ & $5,64 \mathrm{~b}$ & $6,15 \mathrm{~b}$ & $9,21 \mathrm{a}$ & $5,12 \mathrm{~b}$ & $8,79 a$ & $8,16 \mathrm{a}$ & $5,49 \mathrm{~b}$ & $7,35 \mathrm{a}$ & $6,85 a$ & $4,38 \mathrm{~b}$ \\
\hline PbF 3으 Cultivo & $3,28 \mathrm{a}$ & $0,46 \mathrm{~b}$ & $0,46 \mathrm{~b}$ & $2,35 a$ & $2,08 \mathrm{a}$ & $1,00 \mathrm{a}$ & $4,95 \mathrm{a}$ & $0,86 \mathrm{~b}$ & $1,64 \mathrm{~b}$ & $1,23 \mathrm{a}$ & $1,74 \mathrm{a}$ & $1,70 a$ \\
\hline $\mathrm{PbC} 3^{\circ}$ Cultivo & $1,02 \mathrm{~b}$ & $4,20 a$ & $0,10 \mathrm{c}$ & $0,66 a$ & $0,50 a$ & $0,09 \mathrm{~b}$ & $1,22 \mathrm{a}$ & $0,10 \mathrm{~b}$ & $0,05 \mathrm{~b}$ & $0,79 \mathrm{~b}$ & $0,11 \mathrm{c}$ & $1,40 a$ \\
\hline PbR 3ํㅡ Cultivo & $0,65 a$ & $0,43 a$ & $0,53 \mathrm{a}$ & $0,23 a$ & $0,55 a$ & $0,06 \mathrm{a}$ & $0,21 \mathrm{~b}$ & $1,25 \mathrm{~b}$ & $4,87 \mathrm{a}$ & $0,35 \mathrm{~b}$ & $0,89 \mathrm{~b}$ & $7,70 \mathrm{a}$ \\
\hline CdC 1으 Cultivo & $0,13 a b$ & $0,06 \mathrm{~b}$ & $0,24 a$ & $0,10 a$ & $0,23 a$ & $0,18 a$ & $0,15 b$ & $0,35 a$ & $0,24 a b$ & $0,21 \mathrm{a}$ & $0,28 a$ & $0,30 a$ \\
\hline CdC 3 o Cultivo & $0,04 a$ & $0,06 \mathrm{a}$ & $0,06 \mathrm{a}$ & $0,05 a$ & $0,13 a$ & $0,05 a$ & $0,03 a$ & $0,10 a$ & $0,05 a$ & $0,20 a$ & $0,04 \mathrm{~b}$ & $0,05 \mathrm{~b}$ \\
\hline NiC 3oㅡ Cultivo & $6,78 \mathrm{a}$ & $5,50 \mathrm{~b}$ & $5,34 \mathrm{~b}$ & $3,85 \mathrm{c}$ & $7,19 \mathrm{a}$ & $4,39 \mathrm{~b}$ & $6,45 a$ & $1,60 \mathrm{c}$ & $2,70 \mathrm{~b}$ & $6,75 \mathrm{~b}$ & $8,51 \mathrm{a}$ & $5,25 \mathrm{c}$ \\
\hline CrC 3으 Cultivo & $10,04 \mathrm{a}$ & $7,63 \mathrm{~b}$ & $5,03 \mathrm{c}$ & $8,30 \mathrm{~b}$ & $12,90 \mathrm{a}$ & $7,57 \mathrm{~b}$ & $11,05 \mathrm{a}$ & $2,63 \mathrm{~b}$ & $2,93 \mathrm{~b}$ & 9,43 a & $6,81 \mathrm{~b}$ & $3,75 \mathrm{c}$ \\
\hline CrR 1으 Cultivo & $8,43 \mathrm{~b}$ & $13,48 a$ & $12,82 a b$ & $4,50 \mathrm{~b}$ & $12,28 \mathrm{a}$ & $12,52 \mathrm{a}$ & $9,73 \mathrm{a}$ & $14,07 \mathrm{a}$ & $14,42 \mathrm{a}$ & $16,10 \mathrm{a}$ & $13,57 \mathrm{a}$ & $16,07 \mathrm{a}$ \\
\hline CrR 3으 Cultivo & $1,47 a$ & $1,27 \mathrm{a}$ & $0,67 a$ & $0,17 \mathrm{~b}$ & $2,70 a b$ & $5,13 a$ & $0,22 b$ & $4,63 a$ & $4,15 a$ & $0,63 \mathrm{~b}$ & $5,85 a$ & $4,89 a$ \\
\hline
\end{tabular}

As médias seguidas da mesma letra na linha não diferem entre si, a $5 \%$ de probabilidade, pelo teste de Tukey.

bano na cultura do milho após três cultivos sucessivos, observaram redução na produção da planta ao longo dos cultivos. Tais autores atribuíram esse resultado ao esgotamento do efeito do composto na fertilidade do solo.

A máxima produção de matéria fresca foi obtida com a aplicação de 30 t.ha ${ }^{-1}$ do composto no primeiro cultivo, onde as cultivares 'Regina', 'Vitória' e 'Brasil-303' produziram, respectivamente, 333,82; 337,81 e 303,60 g.planta ${ }^{-1}$.

As três cultivares de alface tiveram comportamento semelhante em resposta à aplicação do composto, exceto no segundo cultivo, em que a cultivar 'BR303' teve menor produção devido aos fatores climáticos.

\section{Teor de metais pesados na matéria seca}

\section{a) Teor de $\mathrm{Zn}$}

Entre as cultivares foram constatadas diferenças significativas $(\mathrm{p}<0,05)$ quanto ao teor de $\mathrm{Zn}$ no caule, no segundo e no terceiro cultivo e nas folhas, no terceiro cultivo (Tabelas 3 e 4). Na comparação das médias do teor de $\mathrm{Zn}$ entre as cultivares, observou-se que a cultivar 'Regina' apresentou maior teor desse elemento no caule no terceiro cultivo. No segundo cultivo, tal cultivar não diferenciou da BR303. Já nas folhas, as cultivares 'Regina' e 'Vitória' tiveram a mesma média, porém superior à da cultivar 'BR-303'
A regressão linear do teor de $\mathrm{Zn}$, em função das doses do composto, foi significativa para o caule no primeiro cultivo e para as folhas no primeiro e no segundo cultivo (Tabela 5). Não houve significância da regressão no terceiro cultivo, indicando, provavelmente, o esgotamento desse elemento no solo. Jones \& Jarvis (1981) citaram que a estabilidade da ligação Zn-matéria orgânica é relativamente fraca, podendo ser facilmente liberada para ser absorvida e, consequientemente, persistir menos tempo no solo.

O valor máximo observado na matéria seca da planta (Tabela 6) está abaixo dos níveis considerados fitotóxicos citados por Marschner (1995), que variam de 400 a $500 \mu \mathrm{g} / \mathrm{g}$ na matéria seca. Costa (1994) estimou que, em dose de aproximadamente 20 t.ha $^{-1}$ de composto de lixo, a alface pode acumular até $81,47 \mu \mathrm{g} / \mathrm{g}$ desse elemento na matéria seca foliar.

Na tabela 7, são comparadas as médias dos teores de metais pesados entre as partes da planta, em cada dose de composto de lixo. Nota-se que o Zn, no primeiro e no segundo cultivo teve maior teor na raiz do que no caule e folhas. Embora no terceiro cultivo não tenha havido diferença significativa entre as médias, percebe-se a tendência de maior teor de $\mathrm{Zn}$ na raiz. Esses resultados estão de acordo com os obtidos por Dechen et al. (1991), que concluíram que as raízes concentram mais $\mathrm{Zn}$ do que a parte aérea.

\section{b) Teor de $\mathrm{Cu}$}

Foram constatadas diferenças significativas $(p<0,05)$ entre as cultivares, quanto ao teor de $\mathrm{Cu}$ nas raízes no primeiro e no segundo cultivo e no caule e nas folhas no terceiro cultivo (Tabelas 3 e 4$)$.

O aumento das doses do composto aumentou linearmente, no primeiro cultivo, o teor de $\mathrm{Cu}$ nas raízes e no caule. Nos demais cultivos não foi constatado nenhum efeito significativo (Tabela 5).

$\mathrm{O} \mathrm{Cu}$ não atingiu níveis de fitotoxicidade em nenhuma das partes da planta. O teor máximo observado na planta foi $16,33 \mu \mathrm{g} / \mathrm{g}$ (Tabela 6). Furlani et al. (1978) citaram que, normalmente, o teor de $\mathrm{Cu}$ na alface varia de 5 a 13,9 $\mu \mathrm{g} / \mathrm{g}$. Segundo Marschner (1995), os teores considerados fitotóxicos de Cu são de 20 a 30 $\mu \mathrm{g} / \mathrm{g}$ na matéria seca das folhas.

Na Tabela 7 nota-se que apenas no primeiro cultivo houve maior concentração de $\mathrm{Cu}$ no caule, chegando a 55\% a mais do teor nas folhas e tendo semelhantes proporções, para os demais cultivos, nas raízes, no caule e nas folhas. Isso indica que o $\mathrm{Cu}$ foi translocado para a parte aérea com relativa facilidade, como atestou Alloway (1990).

\section{c) Teor de $\mathbf{P b}$}

Foram observadas diferenças significativas $(\mathrm{p}<0,5)$ do teor de $\mathrm{Pb}$ entre as 
cultivares (Tabelas 3 e 4). Todavia, nenhuma cultivar se destacou, observando-se comportamento diferenciado nas doses e nos cultivos.

O efeito da dose do composto sobre o teor de $\mathrm{Pb}$ foi significativo no primeiro cultivo nas raízes e no terceiro cultivo nas folhas da cultivar 'BR-303' (Tabela 5$)$.

O teor máximo observado foi 4,95 $\mu \mathrm{g} / \mathrm{g}$ no caule (Tabela 6). Costa (1994), aplicando doses de 90 t.ha- ${ }^{1}$ de composto orgânico de lixo, detectaram $6,33 \mu \mathrm{g} /$ $\mathrm{g}$ na matéria seca das folhas da alface. Boon \& Soltanpour (1992), analisando plantas cultivadas em solos com altos teores de $\mathrm{Pb}$, encontraram até $45 \mu \mathrm{g} / \mathrm{g}$ na parte aérea da alface e não fizeram nenhuma referência a quaisquer efeitos fitotóxicos.

Observa-se na Tabela 7 que não houve um padrão de distribuição do $\mathrm{Pb}$ na planta. Alloway (1990) citou que a translocação do $\mathrm{Pb}$ é muito influenciada pelo estado da planta. Em ótimas condições de crescimento, o $\mathrm{Pb}$ precipita-se nas paredes celulares das raízes como compostos poucos solúveis, sendo então pouco transportados para a parte aérea. Todavia, esse mesmo autor mencionou ainda que a absorção e a translocação do $\mathrm{Pb}$ para a parte aérea podem variar também em razão da estação do ano. No outono e inverno há maior translocação para a parte aérea do que nas outras estações.

Tabela 4. Médias relacionadas com os efeitos gerais das cultivares sobre o teor de $\mathrm{Zn}, \mathrm{Cu}$, $\mathrm{Pb}, \mathrm{Cd}$, Ni e Cr na matéria seca das folhas $(\mathrm{F})$, do caule (C) e das raízes (R) de três cultivares de alface adubadas com composto orgânico de lixo urbano. Viçosa, UFV, 1995/1996.

\begin{tabular}{|c|c|c|c|}
\hline \multirow{3}{*}{ Variável } & \multicolumn{3}{|c|}{ Cultivar } \\
\hline & Regina & Vitória & BR-303 \\
\hline & \multicolumn{3}{|c|}{$\mu \mathbf{g ~ g}^{-1}$} \\
\hline ZnF 3으 Cultivo & $63,86 a$ & $60,55 \mathrm{a}$ & $49,55 \quad b$ \\
\hline ZnC 2o Cultivo & $59,68 \mathrm{a}$ & $50,39 \quad b$ & $56,10 \mathrm{a}$ \\
\hline CuF 3으 Cultivo & 9,32 a & $8,27 a b$ & $6,89 b$ \\
\hline CuR 1을 Cultivo & $11,59 a b$ & $10,73 b$ & $13,24 a$ \\
\hline CuR 2o Cultivo & $10,01 \quad b$ & $9,82 \quad b$ & $13,34 \mathrm{a}$ \\
\hline PbC 1ㅇ Cultivo & $4,12 \mathrm{a}$ & $1,81 \quad b$ & $0,88 \quad b$ \\
\hline PbR 1을 Cultivo & $0,94 \quad b$ & $1,61 \mathrm{ab}$ & $2,74 \mathrm{a}$ \\
\hline CdF 2o Cultivo & $0,10 a$ & $0,08 a b$ & $0,05 \quad b$ \\
\hline CdF 3으 Cultivo & $0,07 a$ & $0,02 \quad b$ & $0,02 \quad b$ \\
\hline CdC $2^{\circ}$ Cultivo & $0,12 b$ & $0,19 a$ & $0,16 a b$ \\
\hline CdR 1ㅇ Cultivo & $0,05 \quad b$ & $0,13 a$ & $0,12 a b$ \\
\hline NiF 1은 Cultivo & $3,05 a b$ & $1,76 \quad b$ & $3,57 \mathrm{a}$ \\
\hline NiC 2o Cultivo & $4,69 a$ & $3,27 \quad b$ & $2,98 \quad b$ \\
\hline NiR 3으 Cultivo & $6,79 a$ & $5,04 \quad b$ & $3,73 \quad c$ \\
\hline CrC 2 o Cultivo & $9,23 \mathrm{a}$ & $7,03 a b$ & $3,79 \quad b$ \\
\hline CrR 2o Cultivo & $2,02 \quad b$ & $6,91 \mathrm{a}$ & $5,19 a$ \\
\hline
\end{tabular}

As médias seguidas da mesma letra na linha não diferem entre si, a $5 \%$ de probabilidade, pelo teste de Tukey.

\section{d) Teor de Cd}

Observou-se diferenças significativas no teor de $\mathrm{Cd}$ entre as cultivares (Tabelas 3 e 4). Uma vez que nenhuma cultivar se destacou, tais diferenças podem não ser atribuídas ao efeito dos tra- tamentos e sim a outros fatores, como as condições ambientais nos diferentes cultivos e também ao baixo teor de $\mathrm{Cd}$ no composto.

$\mathrm{Na}$ análise de regressão da dose do teor de Cd na matéria seca (Tabela 5),

Tabela 5. Estimativas dos efeitos gerais dos teores de metais pesados (Y) na matéria seca das folhas, caule e raízes de três cultivares de alface, em três cultivos, em função de doses de composto de lixo urbano (X) . Viçosa, UFV, 1995/1996.

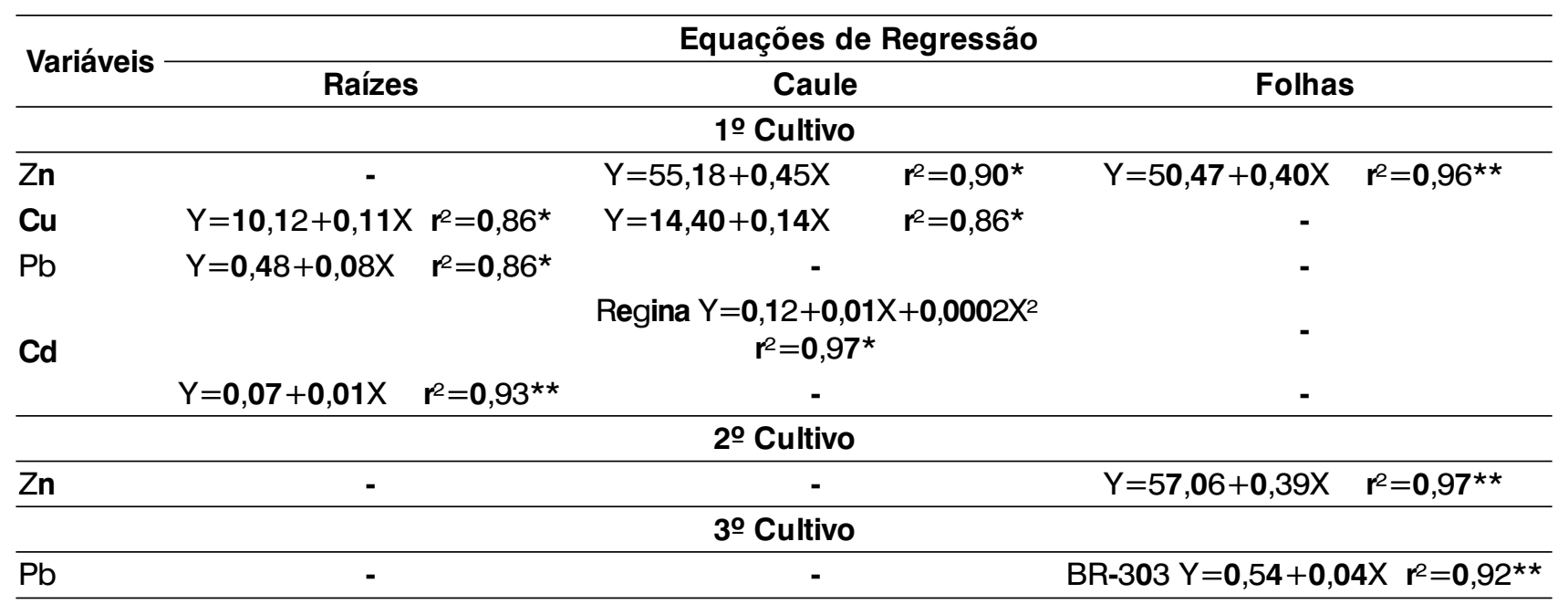

**, significativos a 5 e $1 \%$ pelo teste $\mathrm{F}$, respectivamente. 
ajustaram-se o modelo linear simples para raízes e o modelo quadrático para o caule da cultivar 'Regina' no primeiro cultivo. No terceiro cultivo não houve efeito significativo do composto sobre o teor de Cd na planta, o que pode estar relacionado ao teor relativamente baixo no composto e, consequentemente, no teor disponível no solo.

Observando o teor máximo de $\mathrm{Cd}$ determinado na planta (Tabela 6), notase que o maior teor obtido foi de 0,53 $\mathrm{mg} / \mathrm{g}$ nas folhas. Todavia, esse teor se mostrou bem abaixo do nível conside- rado fitotóxico por Bakers \& Bowers (1988), citados por Amaral (1991), que é de $50 \mu \mathrm{g} / \mathrm{g}$ na matéria seca.

No primeiro cultivo houve maior concentração do $\mathrm{Cd}$ nas folhas (Tabelas 7). No segundo e no terceiro cultivo, não se observou um padrão da distribuição do Cd nas partes da planta. Malavolta (1994) citou que em plantas de feijão o $\mathrm{Cd}$ se acumula mais nas folhas do que em outras partes da planta.

\section{e) Teor de $\mathrm{Ni}$}

Entre as cultivares foram observadas diferenças $(\mathrm{p}<0,05)$ no teor de $\mathrm{Ni}$
Tabela 6. Valores máximos observados de $\mathrm{Zn}, \mathrm{Cu}, \mathrm{Pb}, \mathrm{Cd}, \mathrm{Ni}$ e Cr na matéria seca da alface adubada com composto de lixo urbano. Viçosa, UFV, 1995/1996.

\begin{tabular}{cr}
\hline Elemento & $\begin{array}{c}\text { Valor máximo } \\
\left(\boldsymbol{\mu} \mathbf{g ~ g}^{-1}\right)\end{array}$ \\
\hline $\mathrm{Zn}$ & 111,61 \\
$\mathrm{Cu}$ & 16,33 \\
$\mathrm{~Pb}$ & 4,95 \\
$\mathrm{Cd}$ & 0,53 \\
$\mathrm{Ni}$ & 7,19 \\
$\mathrm{Cr}$ & 16,68 \\
\hline
\end{tabular}

Tabela 7. Médias dos teores de metais pesados na matéria seca das folhas, do caule e das raízes da alface adubadas com composto orgânico de lixo urbano. Viçosa, UFV, 1995/1996.

\begin{tabular}{|c|c|c|c|c|c|c|c|c|c|}
\hline \multirow[b]{2}{*}{ Elemento } & \multicolumn{3}{|c|}{ Primeiro Cultivo } & \multicolumn{3}{|c|}{ Segundo Cultivo } & \multicolumn{3}{|c|}{ Terceiro Cultivo } \\
\hline & Folhas & Caule & Raízes & Folhas & Caule & Raízes & Folhas & Caule & Raízes \\
\hline & \multicolumn{9}{|c|}{$\mu \mathbf{g ~ g}^{-1}$} \\
\hline \multicolumn{10}{|c|}{0 t ha $^{-1}$} \\
\hline$\overline{Z n}$ & $50,17 b$ & b 52,05 b & $75,60 a$ & $57,84 \mathrm{~b}$ & $56,96 \mathrm{~b}$ & 95,36 a & 57,35 a & a 57,58 a & $60,26 a$ \\
\hline $\mathrm{Cu}$ & $12,68 \mathrm{c}$ & c 22,68 a & $16,73 \mathrm{~b}$ & $15,23 a$ & $17,57 \mathrm{a}$ & $16,57 \mathrm{a}$ & $14,23 \mathrm{a}$ & $10,03 a b$ & $11,04 a b$ \\
\hline $\mathrm{Pb}$ & $0,91 a$ & $1,49 a$ & $0,75 a$ & $2,27 a$ & $1,22 \mathrm{ab}$ & $0,58 \mathrm{~b}$ & $1,40 \mathrm{~b}$ & 4,48 a & $0,58 \mathrm{~b}$ \\
\hline $\mathrm{Cd}$ & $0,91 \mathrm{a}$ & $0,13 \mathrm{~b}$ & $0,08 \mathrm{~b}$ & $0,10 a$ & $0,15 a$ & $0,12 a$ & $0,03 \mathrm{~b}$ & $0,05 a b$ & $0,09 a$ \\
\hline $\mathrm{Ni}$ & $2,97 a$ & 3,43 a & $3,26 a$ & $4,18 a$ & $3,94 \mathrm{a}$ & $2,13 a$ & 5,99 a & 5,96 a & 5,45 a \\
\hline $\mathrm{Cr}$ & $13,97 \mathrm{~b}$ & b 27,64 a & $23,75 \mathrm{a}$ & $17,64 \mathrm{a}$ & $10,81 \mathrm{ab}$ & $7,04 \mathrm{~b}$ & $18,18 \mathrm{a}$ & $13,96 \mathrm{a}$ & $2,47 \mathrm{~b}$ \\
\hline \multicolumn{10}{|c|}{$10 \mathrm{t} \mathrm{ha}^{-1}$} \\
\hline $\mathrm{Zn}$ & $54,79 b$ & b 54,22 b & 74,05 a & $60,26 \mathrm{~b}$ & $56,96 \mathrm{~b}$ & $89,08 \mathrm{a}$ & 57,08 a & a 56,41 a & 61,69 a \\
\hline $\mathrm{Cu}$ & $13,62 \mathrm{c}$ & c 26,02 a & $18,53 \mathrm{~b}$ & $16,90 \mathrm{a}$ & $18,85 a$ & $17,52 \mathrm{a}$ & $14,14 a$ & a 11,38 a & $15,43 \mathrm{a}$ \\
\hline $\mathrm{Pb}$ & $0,97 \mathrm{a}$ & $2,30 \mathrm{~b}$ & $0,87 a$ & $2,14 a$ & $1,18 a b$ & $0,15 \mathrm{~b}$ & $0,76 \mathrm{~b}$ & $3,05 a$ & $2,31 a b$ \\
\hline $\mathrm{Cd}$ & $0,98 a$ & $0,17 \mathrm{~b}$ & $0,09 \mathrm{~b}$ & $0,04 a$ & $0,12 \mathrm{a}$ & $0,12 a$ & $0,03 a$ & 0,07 a & $0,06 a$ \\
\hline $\mathrm{Ni}$ & $2,57 \mathrm{a}$ & 4,15 a & $2,87 a$ & 5,08 a & $4,08 a$ & $1,74 a$ & $4,55 \mathrm{a}$ & 5,14 a & $5,72 a$ \\
\hline $\mathrm{Cr}$ & $13,07 \mathrm{~b}$ & $36,37 \mathrm{a}$ & $19,53 \mathrm{~b}$ & $15,82 a$ & 14,17 a & $8,43 a$ & 19,18 a & a 16,34 a & $5,84 \mathrm{a}$ \\
\hline \multicolumn{10}{|c|}{20 t ha $^{-1}$} \\
\hline $\mathrm{Zn}$ & $60,01 b$ & $b \quad 63,33 a b$ & 72,57 a & $63,99 a b$ & $54,97 \quad b$ & $76,34 \quad a$ & $62,16 a$ & a 61,58 a & 62,25 a \\
\hline $\mathrm{Cu}$ & $14,05 \mathrm{c}$ & c 30,73 a & $22,13 \mathrm{~b}$ & $16,15 \mathrm{a}$ & 18,17 a & $16,98 \mathrm{a}$ & 14,09 a & $12,47 \mathrm{a}$ & 12,51 a \\
\hline $\mathrm{Pb}$ & $0,76 \mathrm{~b}$ & $3,05 \mathrm{a}$ & $2,31 a b$ & $2,93 a$ & $2,30 \mathrm{a}$ & $0,48 \mathrm{~b}$ & $2,48 a$ & 4,13 a & $2,11 a$ \\
\hline $\mathrm{Cd}$ & $0,76 a$ & $0,24 a b$ & $0,10 \mathrm{~b}$ & $0,06 \mathrm{~b}$ & $0,16 \mathrm{a}$ & $0,17 a$ & $0,04 \mathrm{~b}$ & $0,05 a b$ & $0,11 a$ \\
\hline $\mathrm{Ni}$ & $2,31 \quad a$ & $3,78 a$ & $3,10 a$ & $4,07 a$ & $3,44 a$ & $1,58 \mathrm{a}$ & $6,14 a$ & $3,58 \mathrm{~b}$ & $4,55 a b$ \\
\hline $\mathrm{Cr}$ & $11,51 \mathrm{c}$ & c $33,04 \mathrm{a}$ & $25,48 \mathrm{~b}$ & $13,51 \mathrm{a}$ & $12,37 \mathrm{a}$ & $11,02 \mathrm{a}$ & 17,54 a & $\mathrm{a} \quad 11,07 \mathrm{~b}$ & $6,19 \mathrm{~b}$ \\
\hline \multicolumn{10}{|c|}{$30 \mathrm{t} \mathrm{ha}^{-1}$} \\
\hline $\mathrm{Zn}$ & $61,67 b$ & $b \quad 63,75 \mathrm{~b}$ & 74,03 a & $69,65 \mathrm{~b}$ & $55,07 \mathrm{~b}$ & 111,92 a & $55,35 a$ & a 58,41 a & 61,38 a \\
\hline $\mathrm{Cu}$ & $13,80 \mathrm{c}$ & c $30,21 \quad a$ & 21,77 b & $17,05 \mathrm{~b}$ & 22,45 a & $16,80 \mathrm{~b}$ & $11,95 \mathrm{a}$ & a 10,38 a & $11,38 a$ \\
\hline $\mathrm{Pb}$ & $1,05 b$ & $2,17 \mathrm{ab}$ & 3,12 a & $3,39 a$ & $1,23 \mathrm{~b}$ & $0,97 \mathrm{~b}$ & $1,55 \mathrm{a}$ & 3,12 a & $2,97 \mathrm{a}$ \\
\hline $\mathrm{Cd}$ & $1,05 \mathrm{a}$ & $0,26 \mathrm{~b}$ & $0,13 \mathrm{~b}$ & $0,09 \mathrm{~b}$ & $0,19 a$ & $0,23 a$ & $0,04 a$ & 0,09 a & $0,07 a$ \\
\hline $\mathrm{Ni}$ & $3,32 a$ & $3,37 a$ & $4,09 \mathrm{a}$ & $4,97 \mathrm{a}$ & $3,78 \mathrm{a}$ & $7,78 \mathrm{a}$ & $6,48 a$ & $6,84 \quad a$ & $4,90 \mathrm{a}$ \\
\hline $\mathrm{Cr}$ & $10,26 \mathrm{~b}$ & b $\quad 30,79$ a & 30,58 a & $13,85 a$ & 15,53 a & $11,39 \mathrm{a}$ & $13,50 \mathrm{a}$ & a 13,32 a & 7,58 a \\
\hline
\end{tabular}

As médias seguidas da mesma letra na linha, em cada cultivo, não diferem estatisticamente entre si pelo teste Tukey a $5 \%$ de probabilidade. 
(Tabelas 3 e 4). A cultivar 'Regina' apresentou maiores teores no caule no segundo cultivo e nas raízes no terceiro cultivo.

A regressão da dose do composto sobre o teor de Ni na matéria seca da planta não foi significativa para nenhum cultivar e em nenhuma das partes da planta (Tabela 5). O baixo teor desse elemento disponível no solo pode ter sido a causa principal desse resultado.

O teor máximo observado na planta foi de 7,19 $\mu \mathrm{g} / \mathrm{g}$ (Tabela 6). Malavolta (1976) citou que pode haver redução no crescimento das plantas quando o teor de Ni na matéria seca foliar atinge 40 $\mu \mathrm{g} / \mathrm{g}$. De acordo com Marschner (1995), os níveis fitotóxicos desse elemento na matéria seca do tecido vegetal variam entre 10 e $50 \mu \mathrm{g} / \mathrm{g}$. Assim, o máximo teor encontrado está bem abaixo dos limites considerados fitotóxicos.

Observa-se na Tabela 7 que o Ni teve concentração semelhante nas raízes, no caule e nas folhas, exceto no terceiro cultivo para a dose de 20 t.ha- . Cataldo $^{-1}$ et al. (1978) e Alloway (1990) citaram que o Ni é facilmente transportado para a parte aérea das plantas. Por outro lado, Marschner (1995) cita que há diferenças entre as espécies na distribuição de Ni na planta.

\section{f) Teor de $\mathrm{Cr}$}

Foram constatadas diferenças no teor de $\mathrm{Cr}$ entre as cultivares (Tabelas 3 e 4). Todavia, não houve destaque para nenhuma das cultivares, que tiveram comportamento diferenciado nas doses e nos cultivos.

Não houve resposta significativa no teor de Cr da planta em razão das doses em nenhum dos cultivos (Tabela 5), o que pode ser atribuído à baixa disponibilidade desse elemento no solo como uma conseqüência do teor relativamente baixo de $\mathrm{Cr}$ no composto. Tal fato implica que a dose mais alta aplicada (30 t.ha $\left.{ }^{-1}\right)$ não foi suficiente para o incremento de $\mathrm{Cr}$ no tecido vegetal.

O teor máximo de Cr na matéria seca foi $16,68 \mu \mathrm{g} / \mathrm{g}$ (Tabela 6). Os teores considerados fitotóxicos na alface são ainda escassos. Em outras espécies, Malavolta (1976) citou que os valores máximos de $\mathrm{Cr}$ na matéria seca variam de 3,90 a $14,80 \mu \mathrm{g} / \mathrm{g}$, entretanto não mencionou os níveis fitotóxicos.

Considerando o baixo teor disponível de $\mathrm{Cr}$ no solo e o fato de não terem sido constatados quaisquer efeitos de fitotoxicidade nas plantas, verificou-se que os teores desse elemento na matéria seca estavam bem abaixo dos níveis fitotóxicos, assim como ocorreu com os demais metais pesados estudados.

Observando a distribuição do Cr na matéria seca da alface (Tabela 7), notase, principalmente no primeiro cultivo, tendência de maior concentração no caule. Já no segundo e terceiro cultivo percebe-se que a maior concentração tende a ser no caule e nas folhas.

Nas condições do presente trabalho, o composto de lixo urbano provocou aumento na produção de alface nos dois primeiros cultivos, mostrando grande potencial de uso no cultivo desta hortaliça. Quanto ao teor de metais pesados na planta, também houve aumento, principalmente no cultivo, seguindo a seguinte ordem decrescente em relação às testemunhas: $\mathrm{Pb}>\mathrm{Cd}>\mathrm{Cu}>\mathrm{Zn}$. Todavia, nenhum dos elementos estudados atingiu teores considerados fitotóxicos.

\section{LITERATURA CITADA}

ALLOWAY, B.J. Heavy metals in soil. London: John Wiley and Sons, 1990. 339 p.

AMARAL, A.S. Liberação de Zn, Fe, Mn, Cd e $\mathrm{Pb}$ de quatro corretivos da acidez do solo e absorção por plantas de alface, em dois solos de diferentes texturas. Viçosa: UFV, 1993. 87 p. (Dissertação mestrado)

BOON, D.Y., SOLTANPOUR, P.N. Lead, cadmium, and zinc contamination of Aspen garden soils and vegetation. Journal Environmental Quality, v. 21, p. 82-86, 1992.

CATALDO, D.A., GARLAND, T.R., WILDUNG, R.E. Translocation of heavy metals in plants. Plant Physiology, v. 62, p. 566-570, 1978.

COSTA, C.A. Crescimento e teores de sódio e de metais pesados da alface e da cenoura adubadas com composto orgânico de lixo urbano. Viçosa: UFV, 1994. 89 p. (Dissertação mestrado)

COSTA, C.A.; CASALI, V.W.D.; CECON, P.R. Teor de $\mathrm{Cu}, \mathrm{Zn}$, e $\mathrm{Cd}$ em cenoura em função de doses de composto de lixo urbano. Horticultura Brasileira, Brasília, v. 15, p. 2940, 1997.

COSTA, C.A.; CASALI, V.W.D.; LOURES, E.G. Teor de metais pesados em alface (Lactuca sativa $\mathrm{L}$.) adubada com composto orgânico de lixo urbano. Revista Ceres, Viçosa, v. 41, p. 629-640, 1994.
DECHEN, H.P., HAAG, H.P., CARMELLO, Q.A. Micronutrientes na Planta. In: FERREIRA, M.E., CRUZ, M.C.P. (ed.). Micronutrientes na agricultura. Piracicaba: POTAFOS/CNPq, 1991. p. 65-78

DEFELIPO, B.V., RIBEIRO, A.C. Análise química do solo (metodologia). Viçosa: Impr. Univ., Universidade Federal de Viçosa, 1981. $17 \mathrm{p}$.

DIXON, F.M.; PREER, J.R.; ABDI, A.N. Metal level in garden vegetables raised on biosolids amended soil. Compost Science and Utilization. v. 3, p. 55-63, 1995.

FRITZ, D.; VENTER, F. Heavy metals in some vegetable crops as influenced by municipal waste composts. Acta Horticulturae. v. 222, p. 51-62, 1988.

FURLANI, A.M.C., FURLANI, P.R. BATAGLIA, O.C. Composição mineral de diversas hortaliças. Brangantia, Campinas, v. 37, p. 33-44, 1978.

GLÓRIA, N.A. Uso agronômico de resíduos. In: DECHEN, A.R.; BOARETTO, A.E.; VERDADE, F.C. (coord.). REUNIÃO BRASILEIRA DE FERTILIDADE DO SOLO E NUTRIÇÃO DE PLANTAS, 20, 1992, Piracicaba. Anais. Piracicaba, 1992. p. 195-212.

HE, X.T.; LOGAN, T.; TRAINA, S.J. Physical and chemical characteristics selected U.S. municipal solid waste composts. Journal Environmental Quality. v. 24, p. 543-552, 1995.

HERNÁNDEZ, T.; GARCÍA, C.; COSTA, F. Utilización de residuos urbanos como fertilizantes orgánicos. Suelo y Planta, v. 2, p. 373 383, 1992.

JONES, L.H.P., JARVIS, S.C. The fate of heavy metals. In: GREENLAND, D.J., HAYERS, M.H.B. (ed.). The chemistry of soil process. New York: John Wiley and Sons, 1981. p. 593620.

MALAVOLTA, E. Fertilizantes e seu impacto ambiental: micronutrientes e metais pesados. Piracicaba: Produquímica, 1994. 153 p.

MALAVOLTA, E. Manual de química agrícola. São Paulo: Ceres, 1976. 528 p.

MARSCHNER, H. Mineral nutrition of higher plants. San Diego: Academic Press, 1995. 889 p.

OGATA, M.G. Os resíduos sólidos na organização do espaço e na qualidade do ambiente urbano: uma contribuição geográfica ao estudo do problema na cidade de São Paulo. Rio de Janeiro: IBGE, 1983. 188 p.

PAINO, V.; PEILlEX, J.; MONTLAHUC, O. Municipal tropical compost: effects on crops and soil properties. Compost Science and Utilization. v. 4, p. 67-69, 1996.

WEIR. C.C.; ALLEN, J.R. Effects of using organic wastes as soil amendments in urban horticultural practices in the district of Columbia. Journal Environmental Science Health. v. 32, p. 323-332, 1997.

WOODBURY, P.B. Trace elements in municipal solid waste compost: a review of potential detrimental effects on plants, biota, and water quality. Biomass and Bioenergy, v. 3, p. 239259, 1992. 